\title{
Impact Assessment of Acetaminophen (paracetamol) on Phaseolus vulgaris L. and Triticum aestivum L. Plants
}

\author{
OCSANA OPRIS ${ }^{1}$, ILDIKO LUNG ${ }^{1}$, MARIA L. SORAN ${ }^{1 *}$, LUCIAN COPOLOVICI ${ }^{2}$, \\ DANA M. COPOLOVICI ${ }^{2}$, MARIA C. COSTA ${ }^{3}$ \\ ${ }^{1}$ National Institute for Research and Development of Isotopic and Molecular Technologies, 67-103 Donat Str., 400293, \\ Cluj-Napoca, Romania \\ ${ }^{2}$ Faculty of Food Engineering, Tourism and Environmental Protection and Institute of Research, Innovation and \\ Development in Technical and Natural Sciences of "Aurel Vlaicu" University, 2 Elena Dragoi Str., Arad 310330, Romania \\ ${ }^{3}$ Centre of Marine Sciences, Universidade do Algarve, Campus de Gambelas, 8005-139 Faro, Portugal
}

\begin{abstract}
In the present work, the effects of acetaminophen (paracetamol) on Phaseolus vulgaris $L$. and Triticum aestivum L. plants, two important vegetables in Romania, were studied. The treatment consisted of sowing the selected plant seed into soil watered with acetaminophen (100 mg kg-1). The measurements of the foliage characteristics, photosynthetic pigments (chlorophylls and carotenoids), the antioxidant capacity, and the amount of the acetaminophen accumulated in the plants were determined in the first and second month of the plant's exposure to acetaminophen. In the case of P. vulgaris, $\beta$-carotene decreased by $57.74 \%$ in the first month and continued the same decreasing trend in the second month of exposure by 58.55\%. The acetaminophen decreased the chlorophylls content by $7.08 \%$ and $13.19 \%$ in comparison with the control plants. In case of T. aestivum plants, the photosynthetic parameters decreased up to $44.80 \%$ compared to control plants, and the carotenoids decreased up to $53.82 \%$. Acetaminophen was detected in P. vulgaris stems at a concentration of 0.44 $\mu g g^{-1} F W$ (after the first month of exposure) and at $0.15 \mu g^{-1} F W$ (after the second month of exposure). The study results indicated a significantly reduction of foliage physiological activity caused by the acetaminophen, suggesting an alteration of the plants antioxidant capacity.
\end{abstract}

Keywords: abiotic stress, carotenoid content, chlorophyll content, photosynthetic rate, acetaminophen (paracetamol)

\section{Introduction}

Nowadays, the contamination of the environment with pharmaceuticals represents an emerging issue in ecotoxicology. Due to the access of the population to healthcare services and the immoderate animal feeding and veterinary practices, the environment is subjected to a significant risk of contamination with a large number and amount of pharmaceuticals $[1,2]$. One of the most consumed pharmaceuticals worldwide is acetaminophen [3, 4]. Acetaminophen (4'-Hydroxyacetanilide, 4Acetamidophenol, N-Acetyl-4-aminophenol, N-(4-hydroxyphenyl) acetamide, paracetamol) is an analgesic drug with antipyretic and anodyne properties used by humans [5-7]. This drug is considered to be safe for human consumption and is being sold without any medical prescription [3]. Nowadays, the consumption of drugs between the teenagers and young adults in the world represents a serious problem [8]. The acetaminophen is produced and consumed in immense quantities and is one of the most over-the-counter drug. The market of acetaminophen was evaluated at 801.3 million USD in 2014 and is expected to reach 999.4 million USD in 2020 [9]. In the U.S., 36.5\% of the interviewed subjects had used acetaminophen in two weeks [10]. In other countries from Europe, such as Germany, $5.2 \%$ of the interviewed subjects used it in 7 days [11], in Sweden $70 \%$ of the interviewed subjects used acetaminophen during three months [12]. Several studies [13, 14] reported that in Romania the self-medication was administrated by $46.6 \%$ from the interviewed population used acetaminophen during six months.

*email: loredana.soran@itim-cj.ro 
This drug it is often determined in the environment, especially in the aquatic environment such as surface waters and wastewaters at concentrations between $0.01-0.3 \mathrm{mg} \mathrm{L}^{-1}[15,16]$. After entering the environment, the fate of acetaminophen is influenced by different processes such as adsorption/desorption, chemical oxidation, hydrolysis, photo-transformation, and biotransformation $[17,18]$. Even more, the acetaminophen is extensively metabolized and only 5\% is excreted unchanged in the urine. In the soil and water arrived different sulfate and glucuronide metabolites of acetaminophen. The list of drugs that produces bioactive metabolites is very long and includes common drugs such as acetaminophen, diclofenac, among many others. Consequently, the excreted bioactive metabolites and the parent drugs that persist in different environment compartments are equally important for consideration for a better risk assessment [19]. Regarding the persistence and fate of acetaminophen there are some uncertainty. Acetaminophen is resistant to direct photolysis under weak irradiation intensities of sunlight [20].

Several studies [21-23] demonstrated that the acetaminophen could cause hepatic necrosis, hepatic lesions, nephrotoxicity, and even deaths to humans and experimental animals in the case of overdoses. The acetaminophen was classified as harmful for aquatic organisms, after a research study performed by Henschel et al. [24] on algae, Daphnia, fish embryos, and bacteria. The possible ecological risk of the acetaminophen was demonstrated in animals [25], but the researches regarding its effects on plants are still limited.

An et al. [5] demonstrated that the acetaminophen inhibits the growth of T. aestivum seedlings. It was also observed that the acetaminophen affects the photosynthetic pigments, soluble protein fractions, and the antioxidant defense system. Kummerová et al. [26] showed that the acetaminophen decreased the photosynthetic pigments, relative chlorophyll fluorescence, and increase the nonphotochemical quenching and the content of soluble proteins and phenolic compounds in Lemna minor plants. Consequently, acetaminophen exposure can cause numerous issues in target or non-target species [5]. Romanian researchers demonstrated that acetaminophen at concentrations of 1, 2, 3 and 4 $\mathrm{g} \mathrm{L}^{-1}$ influences photosynthesis and the emission rate of the volatile organic compounds of $P$. vulgaris [9]. The residues of many chemicals/pollutants enter the environment and directly and indirectly affect the quality of food [27].

This study aimed to investigate the influence of the most consumed pharmaceutical worldwide, acetaminophen, on foliage characteristics of $P$. vulgaris and $T$. aestivum plants, photosynthetic pigments, which are usually monitored to evaluate the plant responses to different types of stress. The antioxidant capacity and the amount of the acetaminophen accumulated in the studied plants were also determined. The $P$. vulgaris and $T$. aestivum plants were selected for this study because are two important vegetables in Romania, widely consumed as food due to their important nutritional values.

\section{Materials and methods}

\subsection{Plant material and growth conditions}

Bean (Phaseolus vulgaris L. Agrosem, Târgu-Mureş, Romania, 18 seeds) and wheat (Triticum aestivum L. cv. 'Lovrin', Fundulea, Romania, 500 seeds) seeds were sown (depth $1 \mathrm{~cm}$ ) in plastic pots $(55 \times 15 \times 11 \mathrm{~cm})$ filled with commercial garden soil $(2.5 \mathrm{~kg})$. The plants were grown at natural light (12 h/24 h light/dark period) in a greenhouse built within INCDTIM, Cluj-Napoca (Romania), monitoring the humidity and temperature. During the experiments, the average day/night temperature registered was $25.48 \pm 2.33 / 18.21 \pm 1.86^{\circ} \mathrm{C}$ and the average humidity was $47.64 \pm 8.18 \%$.

\subsection{Treatment with acetaminophen}

The acetaminophen (99\% purity) was purchased from Sigma-Aldrich (Germany). The molecular formula of the acetaminophen is $\mathrm{C}_{8} \mathrm{H}_{9} \mathrm{NO}_{2}$, and the molecular weight is $151.16 \mathrm{~g} \mathrm{~mol}^{-1}$. After the seeds have been sowed, the treatment with acetaminophen consisted of watering the $2.5 \mathrm{~kg}$ soil with $100 \mathrm{~mL}$ of double distilled water in which $250 \mathrm{mg}$ of acetaminophen were dissolved. Thus, $100 \mathrm{mg}$ of acetaminophen corresponded to $1 \mathrm{~kg}$ of soil. The control plants were grown in soil without 
acetaminophen treatment. Subsequently, the plants were watered with double distilled water each day (48 mL in the first month and $67 \mathrm{~mL}$ in the second month). Thus, in these experiments 3 pots with control of $T$. aestivum, 3 pots with $T$. aestivum treated with acetaminophen, 3 pots of control $P$. vulgaris and 3 pots with $P$. vulgaris treated with acetaminophen were grown. The effects of treatment with acetaminophen were analyzed after 1 and 2 months. For the measurements of each parameter three independent plant samples grown in the same conditions were performed.

\subsection{Gas exchange measurements}

A portable gas exchange system GFS-3000 (Waltz GmbH, Effeltrich, Germany) was used for measurements of leaf gas exchange characteristics: assimilation rate (A), stomatal conductance to water vapor $\left(g_{s}\right)$ and intracellular carbon dioxide concentration $\left(C_{i}\right)$. This system is equipped with an environment-controlled cuvette with an $8 \mathrm{~cm}^{2}$ window area. The experimental condition used for the determination of leaf gas exchange characteristics in the leaves of $P$. vulgaris and T. aestivum were: light intensity of $1000 \mu \mathrm{mol} \mathrm{m} \mathrm{m}^{-2} \mathrm{~s}^{-1}$, leaf temperature of $25^{\circ} \mathrm{C}$, chamber $\mathrm{CO}_{2}$ concentration of 385 $\mu \mathrm{mol} \mathrm{mol}{ }^{-1}$, and $65 \%$ humidity [28]. The targeted photosynthetic characteristics were calculated per unit enclosed leaf area, according to von Caemmerer and Farquhar [29].

\subsection{Extraction and analysis of the pigments}

Leaf samples $\left(4 \mathrm{~cm}^{2}\right)$ of selected plants were taken after gas exchange measurements, frozen in liquid nitrogen, and finely grounded with calcium carbonate. The photosynthetic pigments (zeaxanthin, lutein, $\beta$-carotene, chlorophylls $a$ and $b$ ) were extracted in ice-cold $100 \%$ acetone and centrifuged for 3 $\min \left(0^{\circ} \mathrm{C}\right.$ and $\left.9500 \mathrm{~g}\right)$. The supernatant was retained, and this procedure was repeated with small amounts of acetone until the supernatant remained colorless. The fractions of supernatant were brought with acetone to the final volume of $1 \mathrm{~mL}$ [28]. Before analysis, the obtained plant extracts were filtered with a nylon syringe filter $(0.45 \mu \mathrm{m} \times 13 \mathrm{~mm}$, VWR International, Radnor, PA, USA).

The quantitative determinations of the photosynthetic pigments from the control plants and those treated with acetaminophen were performed with an HPLC-DAD (LC-2010, Shimadzu, Japan) liquid chromatograph. The chromatographic separation was performed using a Kinetex C18 column $(100 \times 3$ $\mathrm{mm}, 2.6 \mu \mathrm{m}$, Phenomenex, Germany) thermostated at $10^{\circ} \mathrm{C}$ with a mobile phase flow rate of $1.5 \mathrm{~mL}$ $\mathrm{min}^{-1}$. The chromatographic elution consisted of buffered ultrapure water $(0.1 \mathrm{M}$ sodium phosphate buffer, $p \mathrm{H}=8$ ) and HPLC grade acetone, both purchased from Sigma-Aldrich (Steinheim, Germany). The chromatographic elution program is described in [28].

\subsection{Extraction and analysis of the accumulated acetaminophen}

$1 \mathrm{~g}$ of plant sample (leaf, stem, and root of $P$. vulgaris and leaf of $T$. aestivum) was taken and immediately frozen in liquid nitrogen. The sample was ground in liquid nitrogen with a mortar and a pestle, and the acetaminophen was extracted in $5 \mathrm{~mL}$ of $0.1 \mathrm{M} \mathrm{HCl}$ and occasionally mixed for $20 \mathrm{~min}$. The extract was centrifuged at $4^{\circ} \mathrm{C}$ for $15 \mathrm{~min}, 9500 \mathrm{~g}$. The extraction was repeated at least three times, with a total volume of $4 \mathrm{~mL} \mathrm{HCl}$. The extract thus obtained was subjected to SPE extraction using Oasis HLB cartridges (500 mg, $6 \mathrm{~mL}$, Waters, USA). The main steps of the SPE extraction of the acetaminophen from plants consisted of conditioning of the cartridge with $10 \mathrm{~mL}$ methanol and 10 $\mathrm{mL}$ ultrapure water, introducing the plant extract previously obtained, and the elution of the acetaminophen retained on the stationary phase was performed with $10 \mathrm{~mL}$ of acetonitrile: methanol $(50: 50, \mathrm{v} / \mathrm{v})$. All SPE steps were performed with a flow rate of $1 \mathrm{~mL} \mathrm{~min}^{-1}$. Using a rotary evaporator $\left(40^{\circ} \mathrm{C}\right)$, the solvent of the sample was removed, and finally, the sample was solubilized in $1 \mathrm{~mL}$ of acetonitrile with $0.1 \% \mathrm{HCOOH}$ : ultrapure water with $0.1 \% \mathrm{HCOOH}(5: 95, \mathrm{v} / \mathrm{v})$. Before the chromatographic analysis, the sample was filtered using a nylon syringe filter.

The analysis of the plant extract was carried out on an HPLC-DAD/MS (Shimadzu, Japan). The MS used was a single quadrupole. The chromatographic separation was performed using a Kinetex C18 column $(100 \times 3 \mathrm{~mm}, 2.6 \mu \mathrm{m}$, Phenomenex, Germany). All the plant extractions were performed in 
triplicate, and each extract was evaluated by HPLC-DAD/MS. The mobile phase used for the chromatographic analysis consisted of acetonitrile with $0.1 \% \mathrm{HCOOH}$ : ultrapure water with $0.1 \%$ $\mathrm{HCOOH}(5: 95, \mathrm{v} / \mathrm{v})$, with isocratic elution and flow rate of $0.3 \mathrm{~mL} \mathrm{~min}^{-1}$. The separation column was thermostated at $30^{\circ} \mathrm{C}$. The injection volume of the plant extract was $20 \mu \mathrm{L}$. Acetaminophen was confirmed based on the retention time from chromatogram and the molecular ion $(\mathrm{m} / \mathrm{z}=152)$ from the MS spectrum obtained with electrospray Ionization in positive mode.

\subsection{Determination of the antioxidant capacity}

Leaf samples $(1 \mathrm{~g})$ of $P$. vulgaris and $T$. aestivum were cut off, frozen in liquid nitrogen and finely minced. The plants were soaked into $25 \mathrm{~mL}$ ethanol: ultrapure water $(60: 40, \mathrm{v} / \mathrm{v})$ and maintained for $10 \mathrm{~min}$. This step was followed by sonication of the obtained mixture for $30 \mathrm{~min}$, at $35^{\circ} \mathrm{C}$. The sonication was performed using an ultrasonic bath Transsonic T 470/H, Elma (Germany). The plant extract was filtered, and the final volume of the extract was brought up to $25 \mathrm{~mL}$ of solvent extraction. The antioxidant capacity was evaluated following a slightly modified procedure reported by BrandWilliams et al. [30]. A volume of $1 \mathrm{~mL}$ of extract was added to $3.9 \mathrm{~mL}$ of DPPH radical methanol solution $\left(0.025 \mathrm{mg} \mathrm{mL}^{-1}\right)$ and after $10 \mathrm{~min}$, maintained in the dark. The absorbance of the mixture was measured at $515 \mathrm{~nm}$ compared to the blank sample ( $1 \mathrm{~mL}$ extract added to $3.9 \mathrm{~mL}$ methanol) using the spectrophotometer (UV-Vis spectrophotometer T80+, PG Instruments, United Kingdom). The results were calculated from the calibration curve and expressed in $\mathrm{mM}$ Trolox $\mathrm{g}^{-1}$ plant. All the determinations were performed in triplicate.

\subsection{Statistical analysis}

The values represent the means of three replications \pm standard error with independent samples of plant. The means were statistically compared with one-way ANOVA followed by Tukey's test using ORIGIN 9 (OriginLab Corporation, Northampton, MA, USA). The statistical analyses were considered significant at $P<0.05$.

\section{Results and discussions}

Overall, in the case of both selected plants, acetaminophen decreased the photosynthetic parameters and pigments, and the antioxidant capacity in comparison with the control plants (Table 1, Figs. 1, 2). Photosynthesis is the most important fundamental biological process supporting growth, uptake of the nutrient, and affecting resistance to different kinds of biotic and abiotic stresses. In our study, in the case of $P$. vulgaris plants, a significant statistical decrease was observed for assimilation rate $(A)$ in both months of the experiment $(44.32 \%$ in the first month and $33.12 \%$ in the second month, Table 1$)$, in comparison with control plants. In the previous studies, Aristilde et al. [31] and Opriş et al. [28] suggested that the different antibiotics inhibited the oxidizing side of photosystem II (PSII). The same mechanism could be associated with acetaminophen treatment. Also, our results are in accordance with results obtained by other researchers which demonstrated that the potential photosynthetic activity of the plant decreases in the presence of the acetaminophen [9].

Reduction was observed for stomata conductance to water vapor $g_{s}(50.62 \%$ in the first month and $33.57 \%$ in the second month of treatment with acetaminophen (Table 1). This effect was associated with carotenoids reduction, which is the presumable precursor for the synthesis of abscisic acid (ABA). Thus, the decrease in stomatal conductance could be due to altered hormonal interactions [28].

A lower decrease but not statistically significant was also observed for intracellular carbon dioxide concentration $\mathrm{Ci}(8.39 \%$ in the first month, $10.08 \%$ in the second month of treatment with acetaminophen (Table 1). This trend could be explain by the fact that stomata were likely to maintain a constant $\mathrm{Ci}$ during the applied stress, which would determine the amount of carbon dioxide directly used in the chloroplast [32]. Such behavior is attributed to stomata limitation [33]. Another recent study [34] indicated a moderate reduction of foliage physiological activity as a response to the stress induced by anti-inflammatory drugs to the green leafy vegetables. 
In the case of $P$. vulgaris plants treated with acetaminophen (first month), the decreases of the analyzed parameters were ranging between $7.08 \%$ (chlorophyll $b$ ) and $57.74 \%$ ( $\beta$-carotene) (Figs. 1 and 2). Photosynthetic parameters, such as pigments content or electron transport attributes, are generally considered to be stress indicators [35]. A reduction in the content of chlorophyll represents a typical stress response and could lead to a decreased light interception [36]. A decrease in chlorophylls content was also found by An et al. [5] in wheat seedlings after 7 days of cultivation with acetaminophen treatment. In our case, the $P$. vulgaris chlorophylls were affected by acetaminophen, inducing a decrease between $7.08 \%$ (for chlorophyll $b$ after the first month of treatment with acetaminophen) and $13.19 \%$ (for chlorophyll $b$ after the second month of treatment with acetaminophen, Figure 1).
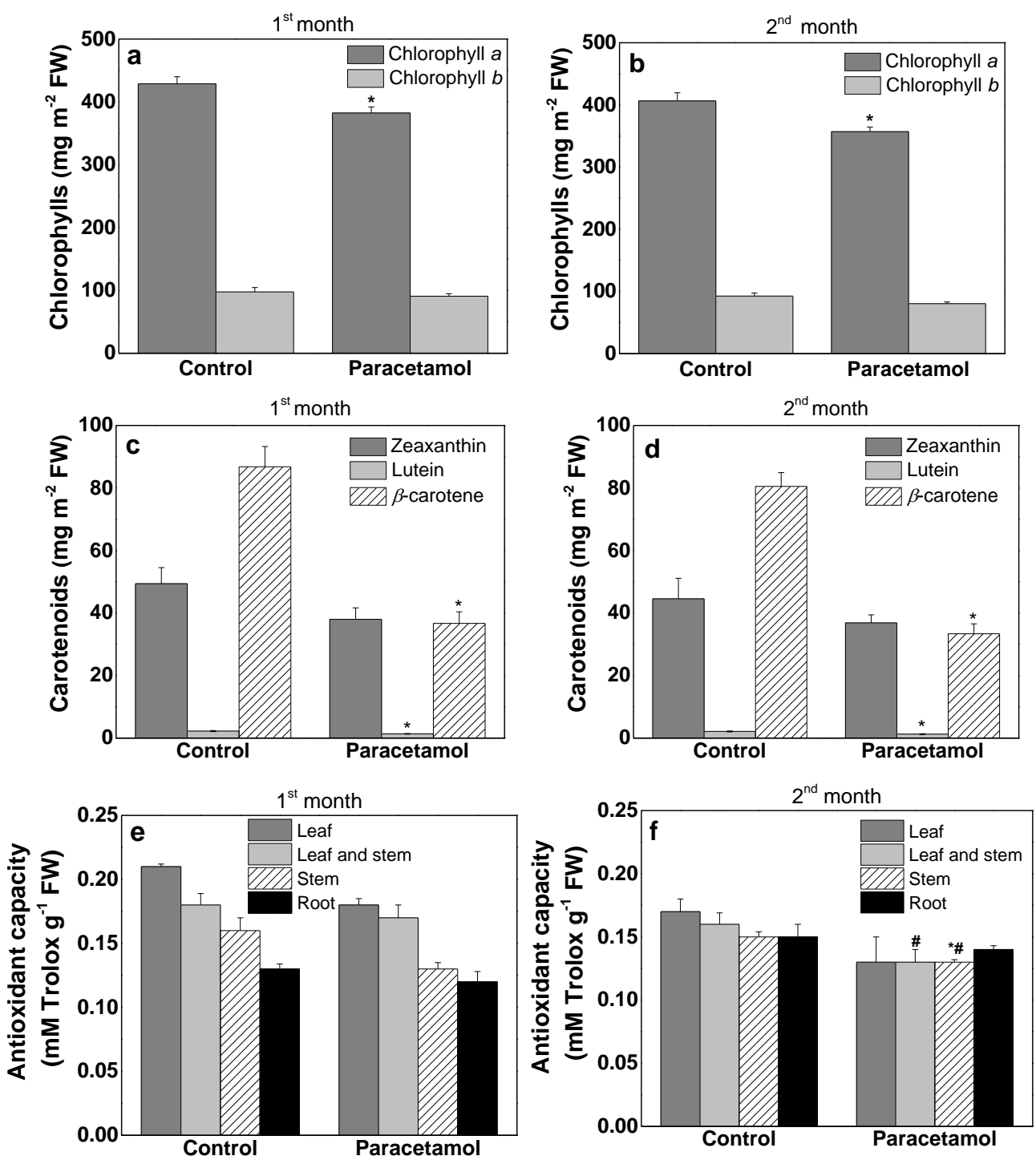

Figure 1. Changes in chlorophylls $(\mathrm{a}, \mathrm{b})$, carotenoids $(\mathrm{c}, \mathrm{d})$ concentration and antioxidant capacity $(\mathrm{e}, \mathrm{f})$ in $P$. vulgaris plants in response to acetaminophen after one month (a, c, e) and two months $(b, d, f)$ of plant growth. Each data point represents the mean $( \pm$ SEM)

of three independent replicate experiments with a different plant. " **" demonstrates statistically significant differences between the acetaminophen treatment and the control $(P<0.05)$; "\#” statistically significant differences between the treated plants for one month and those treated for two months $(P<0.05)$.

In plants, carotenoids are important lipid-soluble antioxidants. These pigments participate as integral 
parts of pigment-binding complexes and in light-harvesting and excess energy quenching [37, 38]. In severe stress conditions, the carotenoids are quickly destroyed and further cannot protect the plant from oxidative stress and photoinhibition [36].

Regarding the photosynthetic pigments, in our case, the most affected parameter analyzed from $P$. vulgaris plants was $\beta$-carotene, with a decrease of $57.74 \%$ in the first month of treatment and continued the same decreasing trend $(58.55 \%)$ in the second month of treatment (Figure 1). The highest effect of acetaminophen on the $P$. vulgaris plants antioxidant capacity during the second month of exposure, was observed on leaves, followed by leaves and stem, stem, and roots. Acetaminophen was detected in $P$. vulgaris stems (Table 1), at a concentration of $0.44 \mu \mathrm{g} \mathrm{g}^{-1}$ fresh weigh (FW, first month) and at $0.15 \mu \mathrm{g}$ $\mathrm{g}^{-1} \mathrm{FW}$ (after the second month of exposure).

T. aestivum plants were also affected by the acetaminophen treatments (Table 1). After the first month of treatment with acetaminophen, the photosynthetic parameters varied from 5.69 to $44.80 \%$, and after two months of treatment from 27.68 to $35.44 \%$. Chlorophylls decreases (Figure 2) were higher after the first month of treatment (chlorophyll $a$ 51.99\% and chlorophyll $b 52.46 \%$ ).
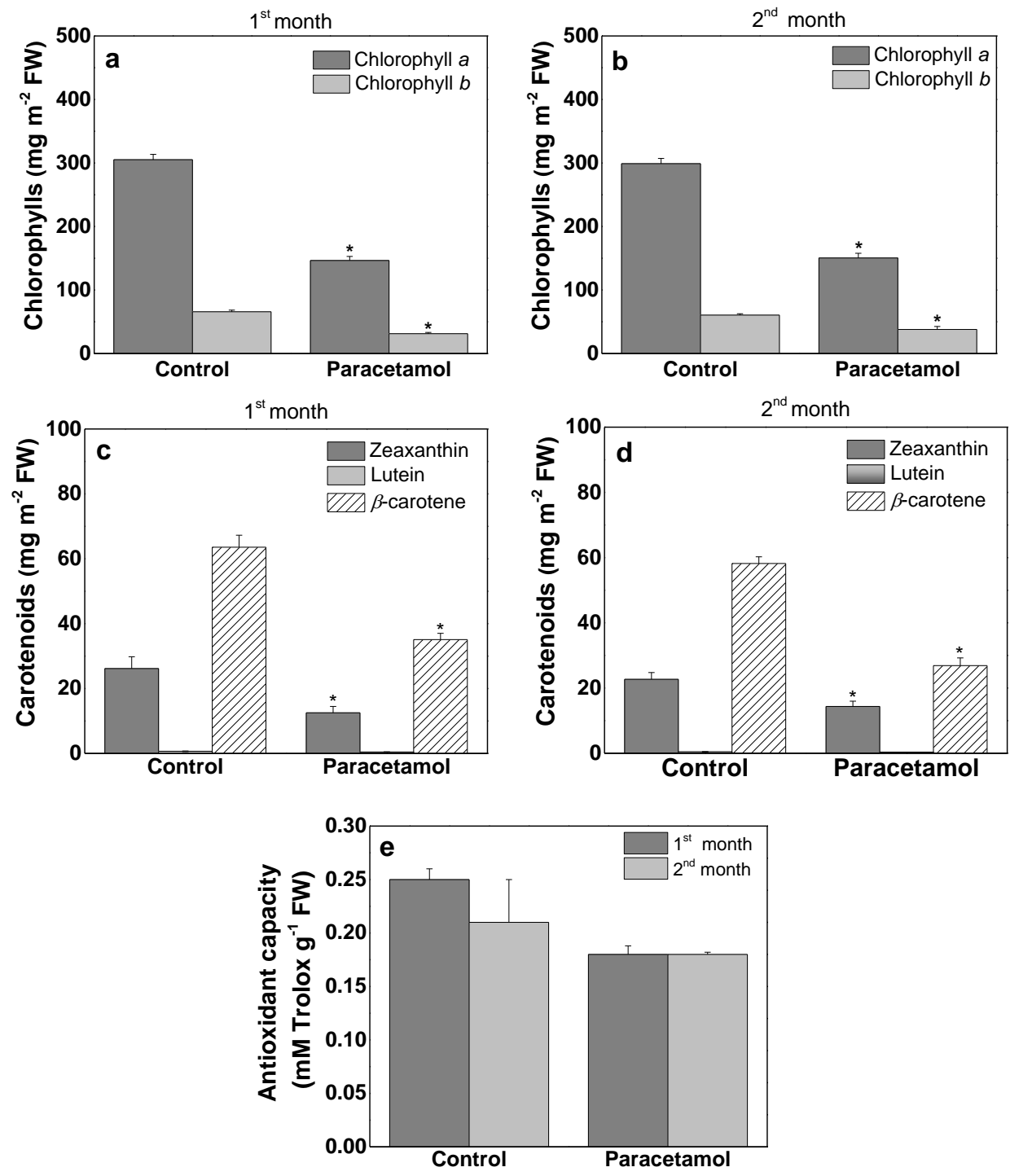

Figure 2. Changes in chlorophylls (a, b), carotenoids (c, d) concentration and antioxidant capacity (e) in T. aestivum plants in response to acetaminophen after one month (a, c, e) and two months (b, d, e) of plant growth. The symbol above the columns stands for statistical differences, as in Figure 1 
Decreases were observed for carotenoids at both times of measurements (Figure 2). In the first month, zeaxanthin decreased by $52.18 \%$, lutein by $31.34 \%$, and $\beta$-carotene by $44.78 \%$. Zeaxanthin is considered to be a precursor for the synthesis of abscisic acid (ABA), the hormone responsible for stomatal closure [39]. This aspect is concluding that reduced stomatal control might reflect altered hormonal interactions. After two months of treatment, the content of zeaxanthin decreased by $36.68 \%$, lutein by $26.09 \%$, and $\beta$-carotene by $53.82 \%$ (Figure 2). A decrease of the $\beta$-carotene in the $P$. vulgaris plants exposed to acetaminophen was also observed by the other researchers [9].

Antioxidant activity represents the ability to inhibit the process of oxidation, which involves a set of different reactions [40]. The antioxidant capacity of the T. aestivum leaves has suffered slight decreases (28.00\% in the first month and $14.28 \%$ in the second month of treatment, Figure 2). In the T. aestivum leaves, acetaminophen was not detected.

\section{Conclusions}

Acetaminophen influenced the growth and development of Phaseolus vulgaris L. and Triticum aestivum L. plants. The results presented in this paper demonstrate moderate effects of the acetaminophen on plant photosynthesis that resulted from alterations in stomatal conductance. The chlorophylls decrease represents the plant response to the stress induced by acetaminophen and could lead to a reduced light interception. In addition, the protection level of the plants against oxidative stress and photoinhibition can be affected due to the decrease of the carotenoids content. Future work could be focused on the influence of different acetaminophen derivatives on plants.

Acknowledgments: This work was supported by a grant of Ministry of Research and Innovation, CNCS - UEFISCDI, project number PN-III-P1-1.1-PD-2016-0484, within PNCDI III, and Nucleu Program, Project PN18-03 0203.

\section{References}

1. CORREIA, B., FREITAS, R., FIGUEIRA, E., SOARES, A.M., NUNES, B., Oxidative effects of the pharmaceutical drug paracetamol on the edible clam Ruditapes philippinarum under different salinities, Comp. Biochem. Physiol. C, 179, 2016, 116-124.

2. KIM, Y., CHOI, K., JUNG, J., PARK, S., KIM, P.G., PARK, J., Aquatic toxicity of acetaminophen, carbamazepine, cimetidine, diltiazem and six major sulfonamides, and their potential ecological risks in Korea, Environ. Int., 33(3), 2007, 370-375.

3. BEBIANNO, M.J., MELLO, A.C.P., SERRANO, M.A.S., FLORES-NUNES, F., MATTOS, J.J., ZACCHI, F.L., PIAZZA, C.E., SIEBERT, M.N., PIAZZA, R.S., GOMES, C.H.A.M., MELO, C.M.R., BAINY, A.C.D., Transcriptional and cellular effects of paracetamol in the oyster Crassostrea gigas, Ecotox. Environ. Safe., 144, 2017, 258-267.

4. YANG, L., YU, L.E., RAY, M.B., Degradation of paracetamol in aqueous solutions by $\mathrm{TiO}_{2}$ photocatalysis, Water Res., 42, 2008, 3480-3488.

5. AN, J.Q., ZHOU, F., SUN, L., ZHANG, J., Ecotoxicological effects of paracetamol on seed germination and seedling development of wheat (Triticum aestivum L.), Hazard. Mater. 16, 2009, 751757.

6. LOURENCAO, B.C., MEDEIROS, R.A., ROCHA-FILHO, R.C., MAZO, L.H., FATIBELLOFILHO, O., Simultaneous voltammetric determination of paracetamol and caffeine in pharmaceutical formulations using a boron-doped diamond electrode, Talanta 78(3), 2009, 748-752.

7. SOLÉ, M., SHAW, J.P., FRICKERS, P.E., READMAN, J.W., HUTCHINSON, T.H., Effects on feeding rate and biomarker responses of marine mussels experimentally exposed to propranolol and acetaminophen, Anal. Bioanal. Chem., 396(2), 2010, 649-656.

8. HORHAT, R.M., VLAICU, B., BAGIU, R., PUTNOKY, S., BAGIU, I., HORHAT, D.I., SZUHANEK, C., SINESCU, C., NEGRUTIU, M.L., NICA, L., A ten-year time laps, regarding drug consumption in the Western part of Romania, Rev. Chim., 69(6), 2018, 1371-1375. 
9. TĂŞCHINĂ, M., COPOLOVICI, D.M., BUNGĂU, S., LUPITU, A.I., COPOLOVICI, L., IOVAN, C., The influence of residual acetaminophen on Phaseolus vulgaris L. secondary metabolites, Farmacia, 65(5), 2017, 709-713.

10. BOUDREAU, D.M., WIRTZ, H., VON KORFF, M., CATZ, S.L., ST JOHN, J., STANG, P.E., A survey of adult awareness and use of medicine containing acetaminophen, Pharmacoepidemiol. Drug Saf., 22, 2013, 229-240.

11. SARGANAS, G., BUTTERY, A.K., ZHUANG, W., WOLF, I.K., GRAMS, D., ROSARIO, A.S., SCHEIDT-NAVE, C., KNOPF, H., Prevalence, trends, patterns and associations of analgesic use in Germany. BMC Pharmacol. Toxicol., 16, 2015, 1-13.

12. HEDENRUD, T., HAKONSE, H., Purchase habits, use of paracetamol, and information sources on a reregulated Swedish pharmacy market: A population-based study, Health Policy, 121, 2017, 35-41.

13. BUNGĂU S., BUNGĂU C., TIT D.M., PALLAG A., The influence of specialized university studies on selfmedication, Rev. Rom. Bioet., 13(1), 2015, 153-158.

14. ŢIŢ, D.M., BUNGAU, S., NISTOR CSEPPENTO, C., COPOLOVICI, D.M., BUHAŞ, C., Disposal of unused medicines resulting from home treatment in Romania. J. Environ. Prot. Ecol., 2016, 17(4), 1425-1433.

15.KASPRZYK-HORDERN, B., DINSDALE, R.M., GUWY, A.J., The occurrence of pharmaceuticals, personal care products, endocrine disruptors and illicit drugs in surface water in South Wales, UK, Water Res., 42(13), 2008, 3498-3518.

16. MIEGE, C., CHOUbERT, J.M., RIBEIRO, L., EUSEBE, M., COQUERY, M., Fate of pharmaceuticals and personal care products in wastewater treatment plants--conception of a database and first results, Environ. Pollut., 157(5), 2009, 1721-1726.

17.LOFFLER, D., ROMBKE, J., MELLER, M., TERNES, T.A., Environmental fate of pharmaceuticals in water/sediments systems, Environ. Sci. Technol., 39(14), 2005, 5209-5218.

18. LORPHENSRI, O., SABATINI, D.A., KIBBEY, T.C.G., OSATHAPHAN, K., SAIWAN, C., Sorption and transport of acetaminophen, 17 $\alpha$-ethynyl estradiol, nalidixic acid with low organic content aquifer sand, Water Res., 41(10), 2007, 2180-2188.

19. CELIZ, M.D., TSO, J., AGA, D.S., Pharmaceutical metabolites in the environment: analytical challenges and ecological risks, Environ. Toxicol. Chem, 28(12), 2009, 2473-2484.

20. PEAKE, B.M., BRAUND, R., TONG, A., TREMBLAY, L.A., The Life-Cycle of Pharmaceuticals in the Environment, New Zealand, Woodhead Publishing, 2015.

21. MITKA, M., FDA asks physicians to stop prescribing high-dose acetaminophen products, J. Am. Med. Assoc., 311(6), 2014, 563.

22. OLALEYE, M.T., ROCHA, B.T., Acetaminophen-induced liver damage in mice: effects of some medicinal plants on the oxidative defense system, Exp. Toxicol. Pathol., 59, 2008, 319-327.

23. RAY, S.D., MUMAW, V.R., RAJE, R.R., FARISS, M.W., Protection of acetaminophen-induced hepato-cellular apoptosis and necrosis by cholesteryl hemisuccinate pretreatment, J. Pharmacol. Exp Ther., 279(3), 1996, 1470-1483.

24. HENSCHEL, K.P., WENZEL, A., DIEDRICH, M., FLIEDNER, A., Environmental hazard assessment of pharmaceuticals, Regul. Toxicol. Pharm. 25(3), 1997, 220-225.

25. BRANDAO, F.P., PEREIRA, J.L., GONCALVES, F., NUNES, B., The impact of paracetamol on selected biomarkers of the mollusc species Corbicula fluminea, Environ. Toxicol., 29(1), 2014, 74-83.

26. KUMMEROVÁ, M., ZEZULKA, Š., BABULA, P., TŘÍSKA, J., Possible ecological risk of two pharmaceuticals diclofenac andparacetamol demonstrated on a model plant Lemna minor, J. Hazard. Mater., 302, 2016, 351-361.

27. RAHOVEANU, A.T., Effects of agricultural activities on the environment, Rev. Chim., 69(11), 2018, 3183-3187.

28. OPRIŞ, O., COPACIU, F., SORAN, M.L., RISTOIU, D., NIINEMETS, Ü., COPOLOVICI, L., Influence of nine antibiotics on key secondary metabolites and physiological characteristics in 
Triticum aestivum: leaf volatiles as a promising tool to assess toxicity, Ecotox. Environ. Safe., 87, 2013, 70-79.

29. VON CAEMMERER, S., FARQUHAR, G.D., Some relationships between the biochemistry of photosynthesis and the gas exchange of leaves, Planta, 153, 1981, 376-387.

30. BRAND-WILLIAMS, W., CUVELIER, M.E., BERSET, C., Use of a free radical method to evaluate antioxidant activity, Food Sci. Technol., 28(1), 1995, 25-30.

31. ARISTILDE, L., MELIS, A., SPOSITO, G., Inhibition of photosynthesis by a fluoroquinolone antibiotic, Environ. Sci. Technol., 44, 2010, 1444-1450.

32. YANG, B., PALLARDY, S.G., MEYERS, T.P., GU, L.H., HANSON, P.J., WULLSCHLEGER, S.D., HEUER, M., HOSMAN, K.P., RIGGS, J.S., SLUSS, D.W., Environmental controls on water use efficiency during severe drought in an Ozark forest in Missouri, USA, Glob. Change Biol., 16, 2010, p. 2252-2271.

33. ZHAO, N., MENG, P., HE, Y., YU, X., Interaction of $\mathrm{CO}_{2}$ concentrations and water stress in semiarid plants causes diverging response in instantaneous water use efficiency and carbon isotope composition, Biogeosciences, 14, 2017, 3431-3444.

34. OPRIŞ, O., CIORITŢĂ, A., SORAN, M.L., LUNG, I., COPOLOVICI, D., COPOLOVICI, L., Evaluation of the photosynthetic parameters, emission of volatile organic compounds and ultrastructure of common green leafy vegetables after exposure to non-steroidal anti-inflammatory drugs (NSAIDs), Ecotox., 28, 2019, 631-642.

35. MALLAKIN, A., BABU, T.S., DIXON, D.G., GREENBERG, B.M., Sites of toxicity of specific photooxidation products of anthracene to higher plants: inhibition of photosynthetic activity and electron transport in Lemna gibba L. G-3(Duckweed), Environ. Toxicol. 17, 2002, 462-471.

36. MUNNE-BOSCH, S., ALEGRE, L., Changes in carotenoids, tocopherols and diterpenes during drought and recovery, and the biological significance of chlorophyll loss in Rosmarinus officinalis plants, Planta, 210, 2000, 925-931.

37. HAVAUX, M., Carotenoids as membrane stabilizers in chloroplasts, Trends Plant Sci., 3, 1998, 147-151.

38. HAVAUX, M., TARDY, F., LEMOINE, Y., Photosynthetic light harvesting function of carotenoids in higher plant leaves exposed to high light irradiances, Planta, 205, 1998, 242-250.

39. MILBORROW, B.V., The pathway of biosynthesis of abscisic acid in vascular plants: a review of the present state of knowledge of ABA biosynthesis, J. Exp. Bot., 52, 2001, 1145-1164.

40.TIRZITIS, G., BARTOSZ, G., Determination of antiradical and antioxidant activity: basic principles and new insights, Acta Biochim. Pol., 57(1), 2010, 139-142.

$\overline{\text { Manuscript received: } 25.06 .2019}$ 